\title{
Beyond Technology in Online Postgraduate Education
}

\author{
Tim Fawns $^{1}$ (D) $\cdot$ Gillian Aitken $^{1}$ (D) $\cdot$ Derek Jones $^{1}$ (D) $\cdot$ Karen $^{\text {Gravett }}{ }^{2}$ (D)
}

Accepted: 16 November 2021 / Published online: 1 December 2021

(c) The Author(s), under exclusive licence to Springer Nature Switzerland AG 2021

Keywords Postdigital education · Online learning · Postgraduate taught education · Technology $\cdot$ Pedagogy $\cdot$ Trust $\cdot$ Honesty $\cdot$ Individualism $\cdot$ Power

\section{Introduction}

Tim Fawns and Gill Aitken are Senior Lecturers in Clinical Education at the University of Edinburgh. They have taught on the fully online MSc Clinical Education ${ }^{1}$ with their colleague, Derek Jones, who has recently retired, for 8, 11, and 7 years, respectively. Together, Gill, Derek, and Tim have created a shared philosophy, and a distributed model of leadership, in order to steer their programme in innovative directions. These directions are informed by values and pedagogical principles, as well as by their practice, and their conversations with students from different countries and healthcare disciplines. At the same time, they have generated a portfolio of research activity around the intersection of online and postgraduate taught education that has involved studying their programme and talking to experts in the field. Within this, their main contributions are around workplace learning (e.g. Aitken 2021; Fawns et al. 2021e), online and hybrid learning (Aitken et al. 2019; Aitken and O'Carroll 2020; Fawns et al. forthcoming 2022), and postdigital conceptions of education (Fawns 2019; Fawns et al. 2019, 2021b). Their book, Online Postgraduate Education in a Postdigital World: Beyond Technology (Fawns et al. 2021f), is the third volume in the Springer Postdigital Science and Education book series. ${ }^{2}$

Karen Gravett is Senior Lecturer in Higher Education. Karen's work focuses on understanding learning and teaching in higher education. Her research explores the role of connections and the relational, student engagement, digital engagement and belonging, and the impact of discourses and narratives in higher education. Her

\footnotetext{
1 See https://www.ed.ac.uk/medicine-vet-medicine/postgraduate/clinical-education. Accessed 13 November 2021.

2 See https://link.springer.com/book/9783030776725. Accessed 13 November 2021.

Tim Fawns

tfawns@ed.ac.uk

1 Edinburgh Medical School, University of Edinburgh, Edinburgh, UK

2 Surrey Institute of Education, University of Surrey, Guildford, UK
} 
latest books are Connections and mattering in higher education: Reimagining relational pedagogy, practice and research (forthcoming 2022); Dominant discourses in higher education: Critical perspectives, cartographies and practice (Kinchin and Gravett forthcoming 2022); and Enhancing student-centred teaching in higher education: The landscape of student-staff partnerships (Gravett et al. 2020).

\section{About the Conversation}

In July 2021, Tim Fawns contacted Karen Gravett to ask if she would be interested in a conversation about their upcoming book. Online Postgraduate Education in a Postdigital World: Beyond Technology (Fawns et al. 2021f) is an edited collection building on the premise that online learning is not separate from the social and material world, and is made up of embodied, socially meaningful experiences. It is founded on a postdigital perspective (Fawns 2019; Fawns et al. 2019) in which, much more than interactions with keyboards, computer screens, hardware, or software, the learning that happens on online postgraduate programmes spills out into professional and informal settings, making connections with what comes before and after any formally scheduled tasks.

Online postgraduate education is growing rapidly, as professionals around the world look to build knowledge and skills that contribute to personal and collective development. This has been recognised within higher education as a key area for economic growth, yet it remains undertheorized, and the quality of these programmes often suffers from approaches that have been developed for on-campus and undergraduate education or, alternatively, simplistic models of e-learning where learning is seen as instrumental, relatively independent of educators. The book explores the ways in which online postgraduate programmes extend beyond digital spaces, and the implications for educational policy and practice.

Tim, Karen, Gill, and Derek met online in September 2021 and talked for an hour. The following is a lightly edited (via email) transcript of that conversation, where we surface some key themes relating to thinking beyond technology in online education, as well as insights and implications for educators to take forward in their own theory-practice.

\section{Pushing Back Against Simplistic Perceptions, Assumptions, and Binaries}

Karen Gravett (KG): Thank you for inviting me to read your book. Can you tell me a little about the inspiration behind this book?

Tim Fawns (TF): I'll start with a brief history of how it happened. I wrote an article for the Postdigital Science and Education about 'Postdigital Education in Design and Practice' (Fawns 2019), based on our work in Edinburgh. The paper challenged the 
hard binary between digital and non-digital, online and on campus. It discussed how most, if not all, education, these days, has some online or digital elements, whether they happen before, during, or after any formal session. All education is also physical, embodied and social.

Following that paper, Petar Jandrić, the editor of the journal, asked if we would like to edit a book about postdigital postgraduate education, to explore further what this postdigital perspective means for different types of contemporary educational practice. We began by writing a commentary (Fawns et al. 2019), arguing that online learning is an embodied, socially meaningful experience, and discussing our experiences of teaching on the MSc in Clinical Education at Edinburgh. It's a fully online programme that caters to different types of healthcare professionals who teach other healthcare professionals. Students are based all over the world, with different cultural and disciplinary backgrounds and settings.

In our commentary, we talked about how, for us, people are the most important thing about online learning; trust and relationships are crucial; and online education cannot easily be scaled up without adding sufficient resources or without developing teaching expertise. The commentary was used as a call for chapters, and we got some great abstracts from people in different institutions, in different parts of the world, who were thinking in similar ways. They might not all have used the term postdigital, but they were thinking about how online education is not really just online- the social and physical aspects matter.

Gill Aitken (GA): The book was primarily a response to some of the frustration we felt towards the perception that online postgraduate study, particularly in healthcare, was a way for the university to generate income. Nobody at that time was talking about the non-financial value of this kind of education. When I first started teaching on an online programme, I was surprised by how meaningful the staff-student relationships were. I was really struck by the deep and rich relationships I was developing with students, and I thought, 'it can't just be me'.

So, the quick answer is: the book was a way to push back a little against the dominant narratives around online postgraduate education, certainly within our institution and, I'm guessing, pretty much elsewhere too. Is that your experience, as well, Karen?

KG: Definitely. One of the things that most resonated with me about your book is that desire to unpack some of the stereotypes and misconceptions about the simplicity of digital learning. For some reason, we love binaries in higher education, and separating online and face-to-face in these rigid categories. This is something that I have been challenging in recent work (e.g. Gravett 2020; Kinchin and Gravett forthcoming 2022). However, I think some of the things that you were saying there, Gill, about online teaching being a space for developing rich and meaningful relationships, would still be quite surprising to many people in our sector. I think discussions frequently revolve around the apparent inability to engage fully online, and I really liked your approach in unpacking these assumptions, and actually considering more thoughtful approaches to situated learning, whether face to face, or hybrid. 


\section{Researching Online Postgraduate Education: Diverse Experiences and Situated Approaches}

KG: I was also interested in your position on the need for research and further discussion around postgraduate education, specifically.

GA: Postgraduate education is such an under-researched area (Aitken and Hayes 2021; Goodyear 2021), despite the rapid expansion of taught Masters that has followed some important work done in the 90's (Knight 1997). As discussed in the book, postgraduate students are, predominantly, studying parttime, sometimes while working as senior professionals with significant practical responsibilities. They are diverse in terms of location, cultural backgrounds and settings, material infrastructures, age and life circumstance. They are often studying advanced concepts and developing capacities for critical appraisal, engaging in-depth with issues of social justice and ethics, and questioning the structures, policies and politics of their workplaces and disciplines. These characteristics influence the considerations of teaching, course design, evaluation, policy and governance and faculty development.

From our own experiences and conversations with our students, we have remained interested in understanding what postgraduate study is about and what we are trying to do as postgraduate educators. Are we trying to help students build up a particular knowledge base, as is often the case in undergraduate studies, or are we trying to do something different? The need to understand our area of education was reinforced a few years ago, when I took on the leadership of the team after the departure of some senior staff in the Medical School. It was quite a sudden change, leading to a lot of conversations about how we could keep the show on the road, how we could maintain credibility, and what was important to us as a team. Our approach involved finding out more about our students and what they wanted and needed from our programme. That's really when we launched our current programme of research.

TF: We saw this as an opportunity to change direction a little, and embed our own shared values throughout our teaching, assessment and curriculum design. One of the interesting things about postgraduate education is that our students have lots of life experience and professional experience and expertise that they bring in. For us, it is such a shame when teachers convey the idea that 'here is the right way to think about education in your discipline' (something that is historically quite pronounced in medical and healthcare education), because we then miss out on a huge diversity of insights that our students bring, not just about their clinical backgrounds and settings but about education as well.

Derek Jones (DJ): Having conversations about where our programme was going, along with the challenge of managing a diverse group of students from all over the world, many of whom live and work in low resource countries, made us think quite a lot about how we could bring together, and make the most of, their different perspectives. It was quite clear that a 'one size fits all' approach wasn't going to work. At that time, we were reading very widely around the educational literature and, quite early on, we had discussions about Derrida's (2000) ethic 
of hospitality that that crops up in the book (Fawns et al. 2021c; Marley et al. 2021) and how we could make space for people coming from lots of different backgrounds.

The ethic of hospitality is about actively avoiding assumptions about the characteristics of the particular students who will arrive on the programme, and responding to them in ways that allow them to be who they are, not who we have decided in advance that they should be. In practice, this means a shift of focus from students as autonomous individuals, to the ways in which emergent environments and relationships are shaped between students, teachers and others, and how those ways value the authentic contributions of each (Ruitenberg 2011). Part of this is making individual students feel that their voices will be heard from the outset, an approach that is often at odds with the push for standardisation within the wider institution.

GA: That relates to some important challenges around how to manage a very able cohort (experienced clinicians from a range of disciplines), most of whom are new to postgraduate study, with academic skills that do not necessarily equip them to succeed in a postgraduate degree. As the team grew over time, we had more capacity to actively look into what our students were getting out of their studies. Even now, despite some published work by the team that looks at this issue (Aitken et al. 2019; Marley et al. 2021), I still don't think we know enough about that. We do know that they don't necessarily get exactly what we set out to teach them (or what they want or expect to learn when they start), and that a lot of the value of their education is around bigger picture stuff (for example, developing an 'infectious curiosity' or expanding their knowledge beyond their immediate disciplines and workplaces (Aitken et al. 2019). I think that's really where the drive to do research and to do the book came from: to continue learning about the value of this form of education and how it manifests in the different settings of our students.

KG: It's also a really significant time to focus on understanding the diverse needs of learners, particularly in relation to online learning, as a result of the Covid-19 pandemic. Our recent experiences have really highlighted how we need to adopt a thoughtful approach to supporting a diversity of learners.

DJ: There is an interesting tension here. Universities as organisations are increasingly interested in allowing space for diversity and being inclusive. But our experience, and the literature, suggests that this is often operationalised in quite a procedural, tick-box way, facilitated by the 'new managerialism' in higher education (Boyd 2014). For example, we see a drive to widen participation sitting alongside high course fees and the requirement to maximise income (Wakeling and Laurison 2017). We've always tried to approach this in a more evolutionary way, working in partnership with students on the programme at the time, rather than imposing a specific structure around inclusivity.

\section{Language and Voices}

KG: A thread that came out of the book as a whole was the different approaches adopted to fostering diversity or creating meaningful learning. One thing, specifically, that I was interested in was: you write about these different strands of work 
that go on in higher education and, in particular, you write that teachers and managers often don't understand what each other is talking about. Different groups are connected and looking at the same issues, but they don't necessarily understand one other. That resonated with me as well. This is certainly something that's an ongoing challenge in our work in terms of how to communicate effectively about an issue like diversity, or connection, or engagement, with different stakeholders. What are your thoughts around how can we develop a common language, and what might the book be able to do in terms of pushing that forward?

GA: In recent times, institutions have been subject to quite a lot of rationalization. Another reason for the book, and for some of our other papers (Fawns et al. 2019, 2021b; Gulasaryan et al. 2021), is that it's a way of pushing back against standardised, reductionist, 'one size fits all' models. What we're trying to do, within postgraduate healthcare education, is to try to bring people together to amplify our voices. However, we can do as much research as we like, but unless these issues are debated at the right level in institutions - until we have people who are effectively representing teachers on central university committees, and representing us authentically, so that our voices are heard-it's difficult to see how things will change.

TF: I agree that activities like our book and our scholarship raise the profile of these discussions more generally, but I also think that the themes within the book, specifically, are quite helpful. Any complex problem is going to need a multi-faceted approach where you attack it from a number of different angles, and the book suggests some of those angles. For example, in the chapter on institutional approaches (Fawns et al. 2021d), we talk about how educational experts and different educational stakeholders (including teachers and students) need to be represented in various leadership constellations (Empson 2017), whether they're longstanding, formal groups like university education committees, or short-term groups. Also, including managers in teaching networks will help them to understand the challenges and support better decision-making.

Another example from the book is the question of whether we can embed more complex pedagogical sensibilities into our evaluation processes so that we can look beyond whether students liked a course, or what the outcomes were, to be more sensitive to some the educational values and ideas that we know are important (Fawns and Sinclair 2021; Marley et al. 2021). Can we give teachers a voice within evaluation, and have a variety of different stakeholders contribute to evaluations that are richer and deeper than some of the more instrumental ones that we see?

Another theme is around discourse. Gill and Sarah (Aitken and Hayes 2021) wrote a chapter about how teaching as a complex endeavour is underrepresented in policy and strategy documents. Often a platform or a strategy, or some innovation, is credited with generating better student experiences, or better outcomes, and the teachers, and even the students, are not recognised for their contribution in prominent forms of discourse. Gill and Sarah reject, for example, the idea that a platform can deliver an experience or outcome, highlighting instead the human labour that goes on. There are teachers who actually know things and have developed expertise that contributes to the quality of educational programmes. It is important to recognise, within policy and strategy documents, that teaching expertise is likely to make any educational initiative more successful. We need experts doing this work. 
As the chapter by Marley et al. (2021) highlights, involving students in decisionmaking, co-design and evaluation can also be very powerful. In fact, I think that university managers will often listen to students more attentively than to teacher voices. Therefore, it is important to create ways that those student voices can be heardgoing beyond whether they're satisfied or not. These are just some examples of how the themes of the book show how we can offer more nuanced approaches to thinking about education.

\section{Navigating Institutions and Crossing Boundaries}

DJ: A strand of work we've been developing recently looks at the interaction of structure and agency, and how these elements constrain or enable what it is that we do. It's not simply a case of needing more teachers in management positions. From a structural point of view, they probably wouldn't get into those management positions unless they're already integrated into the way management currently operates. Even if people start out with different intentions, the logic of universities as organizations starts to shape the ways in which they work. People don't deliberately set out to make things difficult, but they may end up doing that because of how their systems work because they are standardised across the organisation, rather than being sensitive to local considerations. We might then ask how we can make more use of our agency to influence structures.

In my view, as in our programme and teaching, relationships are key. If we are to have any hope of changing the organisational structure, we need to develop relationships with people in management positions. For this, we need to find opportunities to gain a better understanding of why others do things the way they do. For example, our programme administrator has a very blurred boundary between the different aspects of her work and is an integrated member of the academic team. She intimately understands the programme and our students. Although she has to deal with institutional level processes, procedures and policies, she also has a very good understanding of the student perspective, and that helps us all to manage the relationship between the different elements of what we do. We can use this model to think about how we might look for other opportunities for individuals to make connections and have conversations, informally, whenever possible, and to blur the boundaries between roles a bit more.

KG: That's a very positive idea, that through dialogue and through understanding one another, whatever our role in the organization, we can enhance agency and respond to some of those structural constraints that we all experience. Following on from that idea, can you explain who you think should read your book and why?

GA: Most importantly I would like it to generate discussion in teams like ours. When we first started thinking about postgraduate education, we were disappointed with the lack of literature that was out there. I hope the book prompts discussion in other areas about the way forward. What has been refreshing, despite the Edinburgh focus in some of the chapters, is that others, such as Sonia Bussey in Newcastle, have brought in experiences that we recognise (see Bussey 2021). Similarly, with Sarah Hayes at Wolverhampton, there's an understanding, a commonality of 
experiences where (despite the fact institutions are very, very different) all are facing different challenges, a lot of the experiences of teachers seem to be pretty universal.

More generally, the book is aimed at providing theoretical and practical guidance in the design, development and implementation of online, postgraduate programmes. This makes it appropriate as a key text within courses that focus on educational curricula. There are many books relating to online education, but fewer that take a similar theoretical perspective, and none, to our knowledge, that do so with a focus on online, postgraduate education. Our focus on postgraduate contexts differentiates our offering from other books due to its consideration of our students (part-time, professional and potentially experts in their field, internationally-dispersed, different life circumstances) and the focus on the needs of more experienced practitioners or those seeking more critical and theoretical perspectives.

Many books are aimed at helping educators understand student experiences or at theorizing education. Our book does this to some extent, but provides additional and crucial focus on the implications for practice at different levels of engagement with fully online, postgraduate programmes (e.g., teaching, course design, policy and governance, programme-wide evaluation, institutional initiatives and strategies, faculty development). Our aim, then, is to provide a holistic picture of various considerations, at different ecological levels, of what is required to produce good quality, online postgraduate programmes. We hope think that it is relevant to those working in education or digital education; postgraduate, practice-based or professional education (e.g., clinical education); faculty development; and learning technology or instructional design.

Hopefully the book will also be read by those making institutional decisions around how online, postgraduate programmes should be run and supported (i.e., educational programme providers, teachers, learning technologists, faculty developers, educational researchers, and higher education institutional policymakers).

\section{A Postdigital View of Technology and Pedagogy}

KG: Could you talk a little bit more about your view of the relationship between technology and education and pedagogy, and why the concept of postdigital can inform what we do and help clear things up a little bit, or maybe make them even messier?

TF: The relationship between technology and education is really important, and widely misunderstood, I think, especially when it comes to online education. When people consider online teaching, the technology is often foregrounded. During the Covid-19 pandemic, for example, a lot of discourse focused on what technology should be used for, and on potential problems, or worries, about student disengagement. Much of this aligned with a particular model of what online teaching looks like: a Zoom class with students who might or might not have cameras on, and who might not be paying attention to the teacher. That isn't how we think about the relationship between technology and education. We focus more on the relationships that we are building with students (and that they are building with each other) over time, 
and on how different people can bring their knowledge, perspectives and expertise together.

Our students are teachers-often, good ones-who come to us wanting to know more theory and to learn methods of interrogating and developing their practice further. For this reason, the priority for us is making connections between people, between contexts, and between different types of knowledge. Technology is part of this, it shapes the activity that happens within our courses, but it is just one element, alongside the values, purposes, contexts and methods of the teachers and learners. Rather than focus too much on any one of these elements, I think we need to try to deal with them in combination.

Part of this is looking beyond particular technologies and beyond formal sessions, to what the students are actually doing, not just in the moment, but over the weeks and months of a course and the wider programme in which it sits. This comes back to what we wrote in the commentary (Fawns et al. 2019) that launched the call for chapters for the book: online learning doesn't just happen online. It happens wherever the students are (Sun and Goodyear 2020). As teachers, we can set up tasks, resources, ways of communicating, and they can, hopefully, engage with these in many different places (e.g. Boyd 2021). This allows us to think expansively about the possibilities of online education, rather than getting stuck in narrow models of what online learning and online teaching must be.

This is all part of breaking down binary ideas of online or on campus. It's all teaching, really, isn't it, and it's all learning. There may be technologies involved that enable people to communicate in interesting ways, but we don't have to think of online and on campus as totally separate realities. We can think, instead, about the various different types of things that people can do that are going to be helpful for them.

DJ: As Tim says, it's all teaching at the end of the day, and technology is just a part of that. Technology has always created challenges, whether in the form of poor Internet connectivity or, as when I started teaching, a blown light bulb in an overhead projector. Teachers have always been negotiating technology to achieve our particular ends. Each digital, online technology is just another example of how we always have to work with, and around, what's available.

GA: On our programme, we have a foot in both professional and academic camps, so we need ways of patching together those contexts to make what we teach credible (Fawns et al. 2021e). Therefore, for us, it can't just be a one-way transmission of information from the academic (teacher) to the professional (student). We need spaces that allow conversation and dialogue. The same seems to be true for those chapters of the book that are not about health professions education. I think that if you're a teacher who wants to communicate with your students, you'll find a way to do that. Technology can make communication easy, but it doesn't have to be fancy. In fact, it is better if it is quite basic in a lot of cases, but it needs to allow you to be visible, and to allow you to get to know your students and them to get to know you.

TF: Part of the reason for keeping things simple is because institutional constraints mean that only certain technologies are centrally supported. We have to be careful about the terms and conditions of different technologies, and about the ways 
that student data are used. We also have to be careful of what sorts of resources and broadband connections our students have access to if we want to be inclusivetrying to be too fancy with technology makes that difficult. As Gill said, we want to focus on getting to know the students, and on them getting to know us, in ways that don't marginalize people more than necessary.

In her chapter, Rachel Buchanan (2021) talks about an initiative that she introduced in her teacher education course that involved asking her teacherstudents to use Twitter. At first, this seemed like a good opportunity for their professional development. On reflection, she realised she was asking her students to do that encroached on their personal time and made it more difficult to bound their activities within their normal working hours. Although there was value in the exercise, ultimately, it probably wasn't worth the price they paid. She abandoned that activity and simplified things again because she was able to keep the purpose of her course in view. Rachel reminds us that, although there are lots of potentially valuable activities, we need to keep asking 'what is the point', 'what are my values', and 'does the activity I'm asking students to do align with my values'. It's easy to get distracted by the possibilities of technology, but by refocusing on her values and purpose, Rachel was able to see that this wasn't a good activity in the context of the students' wider programme. I think there's an important lesson in there for us.

KG: Yes, I think there's so many useful ideas about focusing and prioritising values, reviewing the purpose of what we're trying to do, and providing spaces for connection and dialogue. These are also some of the underpinning ideas that we enact in our programmes in the Surrey Institute of Education, with the view that teaching and learning is complex and needs a situated, thoughtful, approach. I think having a book like this, where that's one of the underlying threads, is very helpful in developing that conversation.

\section{Trust, Honesty, and Openness}

KG: Something else that comes through a lot in the book is the concept of trust, and how it is very important for meaningful relationships. Could you talk about how, in your view, teachers can foster trust or create trustful relationships within online education.

GA: I think, primarily, it's just being visible, accessible and honest. It's not anything difficult, it's just making sure there's genuineness and authenticity about you and what you bring as a teacher. It's being revealing — appropriately revealing - in what you share of yourself, so that students know you as a person. For example, in our team, we're always quite open about our own limitations, and the limitations of the environments that we teach within. We're not claiming that it's perfect, but it affords more benefits than it causes difficulties.

DJ: We are very intentional about the ways through which we build trust and trusting relationships. The relationship starts from the moment a potential student starts inquiring about the programme. They get to speak to a member of the programme team (an academic or a dedicated administrator) and we try to avoid centralised services in our communication. When we run our live videoconferencing 
sessions, we don't start off with 'this tutorial is about ... and the objectives for this session are ... and by the end of this session, you will be...' Instead, we start with general chat, asking 'how have things been going with you', 'what's been happening this week', or commenting on non-academic things, such as 'that's a nice cat in the background'. Through informal conversation, we get this natural segue from the personal chitchat into the more academic aspects, and then we move naturally back to the less formal (it tends to stay pretty informal throughout) and non-academic towards the end of the session. The personal communication is intertwined in the teaching, and we don't worry about going off on a tangent for a bit.

TF: It's important to note that, if we want students to trust us, then we need to trust our students. There is a lot to say on that, but I will just mention Kyungmee's chapter (Lee 2021). Earlier, Karen, you talked about authenticity and vulnerability. Kyungmee clearly demonstrated the value of that in her chapter by, as Gill also suggested, being open and honest, and admitting that things weren't perfect. She talked with students about mistakes she had made in the past, and made herself vulnerable to the learning community so that they also felt that they could open up. That takes a lot of trust.

Similarly, in our programme, we try not to pretend that we know everything. We try not to pretend that everything is perfect, and we encourage a lot of dialogue around how we do things. We try to always be open to other opinions on our practice, and that requires some vulnerability. I think that we all see that as core to the way we teach, and Kyungmee is the same: she demonstrates the rich connections that can be forged through being vulnerable. That's hard, of course, especially in our current neoliberal context, but I think that if we want students to trust us, then we need to trust them first.

\section{Individualism vs Collaboration: Recognition, Reward, and Finding the Cracks}

KG: One of the things that I want to draw out further is this idea of relationality and community that has come up a lot in our chat today. Derek, you've been talking about the importance of everyone in the teaching team, and we've all talked about the value of students. Often, I struggle, as an academic in higher education, thinking about this tension between ideas of community that we value, and this turn towards the teaching superstar, which is so prevalent (Fawns et al. 2021a). Individualism is an important and entrenched part of higher education culture. Do you have any thoughts that have come out of the book about how we can respond to cultures of individualism, given that we perhaps all share a view that these can be antithetical to collaborative, effective teaching?

GA: I think as an academic community, we have to push back against the trend of focusing recognition on high profile individuals. This is something that the three of us, and the wider team, have talked about a lot. We're very clear that our teaching and the programme runs as a team, with professional services and academic staff working together, and any success does not fall on one person's shoulders. We succeed together, and we fail together. Again, this comes back to trying to influence 
that dominant narrative of individualism. With increasing student numbers over the past couple of years, we have had to move towards more team teaching. While each course has a designated lead, in practice it is facilitated and organised by a group, and it is primarily our shared philosophy and approach is what has underpinned the quality of our programme.

TF: I think all of us dislike teaching awards, in principle. Competition for awards is very time-consuming and brings little or no financial reward. There are so few winners, and award processes tend to highlight particular things that that are easily visible, hiding less visible kinds of labour (Rogers 2019). ${ }^{3}$ In the Conclusion to the book (Fawns et al. 2021a), we talk about how teaching awards favour the already visible. By distributing responsibility, and working in collaborative, team approaches can make individual achievements less visible. It's just not how you play the promotions game in higher education. I suppose that we need to create a new game. To this end, all we can do, I think, is to talk about our values as a team, and as a community, and try to stick to those values. In the absence of actual rewards systems that work for you, you need to keep hold of your values to remind you what you should be doing.

DJ: As you've got the bedrock of the values, there shouldn't be that division between teaching and research — and there is less space for the lone wolf researcher who is not contributing to the collective-because everybody is engaged in teaching and research and discussions. If we've got it right, as long as people buy into the values of the team, although each team member will bring some individual quirks, the team is greater than the sum of its parts. That should, at least, be something to aim for.

KG: It seems like both the book and your programmes operate as spaces for thinking beyond those dominant discourses and actually doing something different. They allow you to position collegiality, team teaching, and a team ethos as key to what happens in those spaces. Bottrell and Manathunga (2019) have written about neoliberalism in higher education, and particularly about how we can find cracks in order to create different spaces that can be very productive and creative. I often think, well, it might be a small space, but maybe the space could gradually grow, and maybe this book is a way to encourage that growth.

\section{Power, Privilege, Subversion, and Aspiration}

KG: I assume, then, that you still believe that there is a space for teachers with the values that we share to function in higher education?

TF: We often talk about the need for working around things and subversion. I don't mean that in a radical or naughty sense. I just mean that teachers are constantly having to use their discretion to enact things in ways that align with their values and

\footnotetext{
3 See Special Issue of Postdigital Science of Education, 3(1), on "Measuring Excellence" in Higher Education', edited by Sarah Hayes. https://link.springer.com/journal/42438/volumes-and-issues/3-1. Accessed 15 November 2021.
} 
how they believe things should be done. That's always been the case, it's not new, it's just that we are always having to do it in a shifting context. We have to keep adapting to what's happening now: what are the new constraints, what are the new systems being imposed on us? But it's the same old thing-we've always had to adapt and subvert things to be able to teach in the ways we believe in, I suppose.

GA: I suspect that there are more subverters out there than we often assume. I've noticed a change, over the years, in academics involved in teaching management or decision-making. Where everyone might have sat around a table, nodding to whomever the senior person was, I now hear people saying 'that's a terrible idea', or 'it doesn't work like that'. It just takes one person. If someone is willing to confront ideas they disagree with, then it gives others confidence to share their views. I suspect this may have been accelerated by the Covid-19 pandemic. People have had their foundations rocked, and alongside figuring out 'what are we going to do', they have been more willing to ask 'why are we doing what we do'. I think people are looking around for experts who know what they're talking about.

KG: There are two things to unpack there. The first is that the Covid-19 pandemic has accelerated remote teaching and created a need for people to stop and think. That has generated all these exciting discussions about the postdigital and breaking the boundaries between online and face-to-face, and about what are we doing and why. The other thing that you mentioned, Gill, was about people having the confidence to actually put their own view across. Obviously, the power that different voices have is not the same, and those with greater experience may have greater power, as may people with other advantages_class, race, gender, and so on. It's great, then, isn't it, if whoever is in a position of power, however small that power might be, puts their head above the parapet. It can give others confidence to speak up and say, 'oh yeah, I agree with that person who wrote that chapter, or who said that comment', and to be confident in their own work, and to go back to their own institution, and say 'well, I'd quite like to do it this way'.

GA: Yes, privilege is such an important issue. Who has privilege, but, equally, who has a voice? Who has permission to articulate those ideas?

KG: Sometimes, I think we want to pretend that we are all in an equal space and that opportunity for dialogue means that participation in dialogue is equally possible for everyone within that space. Remembering that our classrooms and our meeting rooms and our Zoom rooms are not equitable spaces, even though we might wish them to be, is useful. It can help us to remember to support others' voices, and to encourage the coming together of different perspectives.

TF: As teachers, we're never finished developing; we're never finished working on how we do education, or what our values are. There are so many different ways we could approach dialogue with our students, and some are more equitable than others. In our team, we have these principles that we are constantly trying to follow, but one of the important things about them, I think, is that we acknowledge that they're aspirational. We often fall short, but that doesn't mean we abandon them. We just keep working towards them. We've talked about our aspirational principle of the ethic of hospitality, where we aim to create space for whoever the students might be, so that they can turn up and contribute to the development of that space, with us, through dialogue. Can we do this $100 \%$ ? No, because of the imposition of structures 
that Derek was talking about, and because of our own imperfections as teachers. We never manage to entirely create this ethic of hospitality, but we have it as something to continuously work towards.

I think it's crucial, that we never think that we've done inclusivity and diversity, or that we've done equity or trust. We need to keep them as directions to move towards.

\section{What Next?}

KG: Can you tell us a little about how you found the experience of editing this collection? It would also be interesting to find out what you learned from the process as a whole?

GA: Sometimes, you get so caught up in day-to-day stuff that it can feel like just one more thing to do. Looking at it again in preparation for this interview reminded me of how interesting the chapters were! I think the best thing about it has been the opportunity to look around and see what's going on elsewhere, and to engage with different people doing innovative teaching. It has been a brilliant opportunity to take some time to tune into other people's thinking and realise that there are others in similar situations. I was blown away by some of the contributions of the chapter authors. Those ideas, and the community aspect of collaborating on a book with a range of people in different locations, that's what I got out of it the project.

KG: The book might also provide sustenance for those teachers who have felt alone before, or who may not have a collegial team where they can have these conversations.

TF: For me, the book also highlighted how much more there is that could be said about this kind of education. This is one book with 13 chapters, and it could never cover everything that is important. Collectively, we need to do much more work in this space.

KG: What's next, then, for the work in this space or for online postgraduate education more broadly? A massive question to end on!

GA: The easy answer is: what we're actually doing. We are currently looking in more detail at how our students' understandings of teaching are changing through postgraduate study. Tim and I are also going to be doing some related work, with colleagues from another Medical School, on how we define teaching expertise in a postgraduate context.

DJ: The interesting thing about that project is that although the focus is on medical education, much of the discussion is also applicable to other professions (for example, law, teaching, or engineering) where there's an expectation that you are training the next generation of people within your field.

TF: And I guess our focus, going forward, will continue to be on complexity: the interrelationship between technology, the postgraduate context, the actual activity of students, teachers' and students' values, all of these things. The intersection of all of those factors, applied to a particular context, like health professions education, is endlessly fascinating. That's where we would position ourselves as researchers, right? 
GA: I'd say so. It's problematic, isn't it, because you're dragged in different directions. I don't think this kind of research and scholarship is ever finished, but I feel quite satisfied with what we've achieved so far in the time that we've had available to us, within the pressurised sphere we're in. What will be interesting is to see what other people come up with on the back of the work in this book.

\section{References}

Aitken, G. (2021). A Postdigital Exploration of Online Postgraduate Learning in Healthcare Professionals: A Horizontal Conception. Postdigital Science and Education, 3(1), 181-197. https://doi.org/10. 1007/s42438-020-00103-w.

Aitken, G., \& Hayes, S. (2021). Online postgraduate teaching: re-discovering human agency. In T. Fawns, G. Aitken, \& D. Jones (Eds.), Online Postgraduate Education in a Postdigital World: Beyond Technology (pp. 139-159). Cham: Springer. https://doi.org/10.1007/978-3-030-77673-2_8.

Aitken, G., Jones, D., Fawns, T., Sutherland, D., \& Henderson, S. (2019). Using Bourdieu to explore graduate attributes in two online Master's programmes. Advances in Health Sciences Education, 24, 559-576. https://doi.org/10.1007/s10459-019-09885-6.

Aitken, G., \& O'Carroll, S. (2020). Academic identity and crossing boundaries: The role of the Programme Director in Postgraduate Taught Programmes. Teaching in Higher Education, 39(7), 14101424. https://doi.org/10.1080/07294360.2020.1737658.

Boyd, S. (2021). Taking Time to get Messy Outside the Online Classroom. In T. Fawns, G. Aitken, \& D. Jones (Eds.), Online Postgraduate Education in a Postdigital World: Beyond Technology (pp. 21-38). Cham: Springer. https://doi.org/10.1007/978-3-030-77673-2_2.

Boyd, V. (2014). Resisting the tick box: Reflexive use of educational technologies in developing student identities and challenging higher education constructions of disability based on notions of conformity and consistency. International Journal of Disability, Development and Education, 61(4), 377387. https://doi.org/10.1080/1034912X.2014.955789.

Bottrell, D., \& Manathunga, C. (Eds.). (2019). Resisting Neoliberalism in Higher Education, Volume 1: Seeing Through the Cracks. Cham: Palgrave.

Buchanan, R. (2021). Networked Professional Learning in the Postdigital Age: Asking Critical Questions of Postgraduate Education. In T. Fawns, G. Aitken, \& D. Jones (Eds.), Online Postgraduate Education in a Postdigital World: Beyond Technology (pp. 121-138). Cham: Springer. https://doi.org/10. 1007/978-3-030-77673-2_7.

Bussey, S. (2021). Inclusivity in Online Postgraduate Teaching. In T. Fawns, G. Aitken, \& D. Jones (Eds.), Online Postgraduate Education in a Postdigital World: Beyond Technology (pp. 105-120). Cham: Springer. https://doi.org/10.1007/978-3-030-77673-2_6.

Derrida, J. (2000). Hostipitality. Angelaki, 5(3), 3-18. https://doi.org/10.1080/09697250020034706.

Empson, L. (2017). Leading professionals: Power, politics, and prima donnas. Oxford: Oxford University Press.

Fawns, T. (2019). Postdigital Education in Design and Practice. Postdigital Science and Education, 1(1), 132-145. https://doi.org/10.1007/s42438-018-0021-8.

Fawns, T., Aitken, G., \& Jones, D. (2019). Online Learning as Embodied, Socially Meaningful Experience. Postdigital Science and Education, 1(2), 293-297. https://doi.org/10.1007/ s42438-019-00048-9.

Fawns, T., \& Sinclair, C. (2021). Towards Ecological Evaluation of Online Courses: Aiming for Thick Description. In T. Fawns, G. Aitken, \& D. Jones (Eds.), Online Postgraduate Education in a Postdigital World: Beyond Technology (pp. 85-104). Cham: Springer. https://doi.org/10.1007/ 978-3-030-77673-2_5.

Fawns, T., Aitken, G., \& Jones, D. (2021a). A Little More Conversation, A Little Less Factionalisation: Thoughts for The Postdigital Future of Online Postgraduate Education. In T. Fawns, G. Aitken, \& D. Jones (Eds.), Online Postgraduate Education in a Postdigital World: Beyond Technology (pp. 217-232). Cham: Springer. https://doi.org/10.1007/978-3-030-77673-2_12. 
Fawns, T., Aitken, G., \& Jones, D. (2021b). Ecological Teaching Evaluation vs the Datafication of Quality: Understanding Education with, and Around Data. Postdigital Science and Education. 3(1), 65-82. https://doi.org/10.1007/s42438-020-00109-4.

Fawns, T., Aitken, G., \& Jones, D. (2021c). Introduction: A Postdigital Position on Online Postgraduate Education. In T. Fawns, G. Aitken, \& D. Jones (Eds.), Online Postgraduate Education in a Postdigital World: Beyond Technology (pp. xv-xxvi). Cham: Springer.

Fawns, T., Gallagher, M., \& Bayne, S. (2021d). Institutional Contexts in Supporting Quality Online Postgraduate Education: Lessons Learned from Two Initiatives at The University of Edinburgh. In T. Fawns, G. Aitken, \& D. Jones (Eds.), Online Postgraduate Education in a Postdigital World: Beyond Technology (pp. 197-216). Cham: Springer. https://doi.org/10.1007/978-3-030-77673-2_11.

Fawns, T., Mulherin, T., Hounsell, D., Aitken, G. (2021e). Seamful learning and professional education. Studies in Continuing Education. https://doi.org/10.1080/0158037X.2021.1920383.

Fawns, T., Aitken, G, \& Jones, D. (Eds.). (2021f). Online Postgraduate Education in a Postdigital World: Beyond Technology. Cham: Springer.

Fawns, T., Markauskaite, L., Carvalho, L., \& Goodyear, P. (forthcoming 2022). H2m pedagogy: Designing for hybrid learning in medical education. In E. Gil, Y. Mor, Y. Dimitriadis, \& C. Köppe (Eds.), Hybrid Learning Spaces. Berlin: Springer.

Goodyear, P. (2021). Afterwords: Considering the postgraduate, postdigital and postcritical. In T. Fawns, G. Aitken, \& D. Jones (Eds.), Online Postgraduate Education in a Postdigital World: Beyond Technology (pp. 233-256). Cham: Springer. https://doi.org/10.1007/978-3-030-77673-2_13.

Gravett, K. (2020). Feedback literacies as sociomaterial practice. Critical Studies in Education. https:// doi.org/10.1080/17508487.2020.1747099.

Gravett, K., Yakovchuk, N., \& Kinchin, I. M. (Eds.) (2020). Enhancing student-centred teaching in higher education: The landscape of student-staff partnerships. Cham: Palgrave Macmillan.

Gulasaryan, A., Aitken, G., Fawns, T., Jones, D., Napier, J., \& Walker, K. (2021). How can inhabited institutionalism inform the analysis of medical education? Medical Education. https://doi.org/10. 1111/medu.14587.

Kinchin, I. M., \& Gravett, K. (2022). Dominant discourses in higher education: Critical perspectives, cartographies and practice. London: Bloomsbury.

Knight, P. T. (Ed.). (1997). Masterclass: Teaching, learning and curriculum at master's level. London: Cassell.

Lee, K. (2021). Embracing Authenticity and Vulnerability in Online PhD Studies: The Self and a Community . In T. Fawns, G. Aitken, \& D. Jones (Eds.), Online Postgraduate Education in a Postdigital World: Beyond Technology (pp. 63-84). Cham: Springer. https://doi.org/10.1007/ 978-3-030-77673-2_4.

Marley, C., Faye, A., Hurst, E., Moeller, J., \& Pinkerton, A. (2021). Moving Beyond 'You Said, We Did': Extending an Ethic of Hospitality to The Student Feedback Process. In T. Fawns, G. Aitken, \& D. Jones (Eds.), Online Postgraduate Education in a Postdigital World: Beyond Technology (pp. 1-20). Cham: Springer. https://doi.org/10.1007/978-3-030-77673-2_1.

Rogers, G. D. (2019). Why we would be better off without grants and awards in health professional education: A personal view from Australia. Medical Teacher, 41(9), 1081-1082. https://doi.org/10.1080/ 0142159X.2018.1536820.

Ruitenberg, C. (2011). The Empty Chair: Education in an Ethic of Hospitality. In R. Kunzman (Ed.), Philosophy of Education Archive (pp. 28-36). Urbana, IL: Philosophy of Education Society.

Sun, S. Y. H., \& Goodyear, P. (2020). Social co-configuration in online language learning. Australasian Journal of Educational Technology, 36(2), 13-26. https://doi.org/10.14742/ajet.5102.

Wakeling, P., \& Laurison, D. (2017). Are postgraduate qualifications the "new frontier of social mobility'? British Journal of Sociology, 68(3), 533-555. https://doi.org/10.1111/1468-4446.12277.

Publisher's Note Springer Nature remains neutral with regard to jurisdictional claims in published maps and institutional affiliations. 